\title{
Efficient modelling of delamination buckling in composite cylindrical shells under axial compression
}

DOI:

10.1016/j.compstruct.2003.09.050

\section{Document Version}

Accepted author manuscript

Link to publication record in Manchester Research Explorer

\section{Citation for published version (APA):}

Tafreshi, A. (2004). Efficient modelling of delamination buckling in composite cylindrical shells under axial compression. Composite Structures, 64(3-4), 511-520. https://doi.org/10.1016/j.compstruct.2003.09.050

\section{Published in:}

Composite Structures

\section{Citing this paper}

Please note that where the full-text provided on Manchester Research Explorer is the Author Accepted Manuscript or Proof version this may differ from the final Published version. If citing, it is advised that you check and use the publisher's definitive version.

\section{General rights}

Copyright and moral rights for the publications made accessible in the Research Explorer are retained by the authors and/or other copyright owners and it is a condition of accessing publications that users recognise and abide by the legal requirements associated with these rights.

\section{Takedown policy}

If you believe that this document breaches copyright please refer to the University of Manchester's Takedown Procedures [http://man.ac.uk/04Y6Bo] or contact uml.scholarlycommunications@manchester.ac.uk providing relevant details, so we can investigate your claim.

\section{OPEN ACCESS}


Tafreshi, A. June 2004 In : Composite Structures.64, 3-4, p. 511-520 10 p.

\title{
EFFICIENT MODELLING OF DELAMINATION BUCKLING IN COMPOSITE CYLINDRICAL SHELLS UNDER AXIAL COMPRESSION
}

\author{
Azam Tafreshi Aerospace Engineering, School of Engineering, \\ University of Manchester, Oxford Road, \\ Manchester M13 9PL, United Kingdom \\ atafreshi@manchester.ac.uk
}

\begin{abstract}
Composite cylindrical shells and panels are widely used in aerospace structures. These are often subjected to defects and damage from both in-service and manufacturing events. Delamination is the most important of these defects. This paper deals with the computational modelling of delamination in isotropic and laminated composite cylindrical shells. The use of three-dimensional finite elements for predicting the delamination buckling of these structures is computationally expensive. Here combined double-layer and single-layer of shell elements are employed to study the effect of delamination on the global load-carrying capacity of such systems under axial compressive load. It is shown that through-the-thickness delamination can be modelled and analysed effectively without requiring a great deal of computing time and memory. A parametric study is carried out to study the influence of the delamination size, orientation and through-the-width position of a series of laminated cylinders. The effect of material properties is also investigated. Some of the results are compared with the corresponding analytical results. It is shown that ignoring the contact between the delaminated layers can result in wrong estimations of the critical buckling loads in cylindrical shells under compressive load.
\end{abstract}

Keywords: Delamination, composites, finite element method, buckling analysis, laminated cylindrical shells 


\section{Nomenclature}

a

$\overline{\mathrm{a}}=\mathrm{a} / \mathrm{L}$

b

$\mathrm{E}_{11}, \mathrm{E}_{22}, \mathrm{G}_{12}, v_{12}$

$\mathrm{h}_{1}, \mathrm{~h}_{2}$

$\overline{\mathrm{h}}=\mathrm{h}_{1} / \mathrm{t}$

$\mathrm{L}, \mathrm{R}, \mathrm{t}$

$\mathrm{P}_{\mathrm{c}}$

$\mathrm{P}_{\text {cr }}$

$\mathrm{u}_{\mathrm{x}}, \mathrm{u}_{\mathrm{y}}, \mathrm{u}_{\mathrm{z}}$

$\mathrm{x}, \mathrm{y}, \mathrm{z}$

$\psi_{\mathrm{x}}, \psi_{\mathrm{y}}, \psi_{\mathrm{z}}$

$\alpha$ length of delamination

normalized delamination length

delamination width, $(b=\mathrm{R} \alpha)$

material constants

thicknesses of upper and lower sublaminates, respectively

normalized delamination thickness

length, radius and thickness of the overall cylindrical shell, respectively

critical buckling load of an intact cylinder

critical buckling load of a delaminated cylinder

axial, circumferential and radial displacements, respectively

axial, circumferential and radial coordinates, respectively

rotation about the $\mathrm{y}, \mathrm{x}$, and $\mathrm{z}$ axes, respectively

angle of the delamination region (delamination width)

\section{INTRODUCTION}

Laminated composites are gaining importance in aircraft structural applications as a result of their very high strength-to-weight and high stiffness-to-weight ratios. It is known that delaminations are the most frequent causes of failure in laminated structures, particularly under compressive load. Delaminations in composite materials result typically from impact damage or manufacturing imperfections. The presence of delaminations leads to a reduction in the overall buckling strength of the structure. In addition, delaminations tend to grow rapidly under postbuckling loads, causing further reduction in structural strength and leading ultimately to fatal structural failure.

The phenomenon of progressive failure in laminated composite structures is yet to be understood, and as a result, reliable strategies for designing optimal composite structures for desired life and strength are in progress [1,2]. 
For the past two decades analytical and numerical analyses have been carried out by many researchers to analyse delaminated composite structures, considering their buckling and post-buckling behaviour. Almost all of the papers on delamination buckling deal with beams and flat plates [3-10]. The early work belongs to Chai et al. [9] who characterized the delamination buckling models by the delamination thickness and number of delaminations through the laminate thickness.

In a recent study by the author [11] finite element models were developed to study global, local and mixed mode buckling behaviour of composite flat plates with embedded delamination under compression. The results were in agreement with the corresponding experimental results. In comparison with the other numerical models, it was shown that embedded delaminations can be modelled and analysed effectively without requiring a great deal of computing time and capacity.

There has been a reasonable amount of work on buckling and post-buckling behaviour of cylindrical shells and panels [12-18]. Due to its mathematical complexity and modelling, very limited information on the subject of delamination buckling of cylindrical shells and panels is currently available [19-24]. This paper studies the effect of delamination on the global load-carrying capacity of isotropic and laminated cylindrical shells under axial compressive load.

The use of three-dimensional finite elements for the modelling of delamination in cylindrical shells is computationally expensive. In the present study an efficient modelling approach is employed for investigation of buckling behaviour of these structures. This requires less computing time and space for the same level of accuracy. Some parametric studies are performed to investigate the influence of the delamination size, orientation and through-the-thickness position on the critical loads of a series of isotropic and delaminated cylindrical shells. The effect of material properties is also investigated. 
The analysis has been carried out using ABAQUS 6.3 which is available on the mainframe computer, Bezier, at Manchester Computing centre.

\section{FINITE ELEMENT MODELLING AND VERIFICATION}

Fig. 1a shows the geometry of a typical cylindrical shell with a rectangular delamination (axb) under axial compressive loading, where the first measurement (a) is in the axial direction, the second measurement (b) is in the circumferential direction and $b=R \alpha$. Angle $\alpha$ denotes the region of the delamination and $\mathrm{R}$ is the radius of the cylinder. $\mathrm{h}_{1}$ and $\mathrm{h}_{2}$ are the thicknesses of the upper and lower sublaminates, respectively. The nondimensional parameter $\overline{\mathrm{h}}=\mathrm{h}_{1} / \mathrm{t}$ is used to describe the delamination thickness, where $t$ is the thickness of the cylinder.

A differential element of an intact cylindrical shell segment with the coordinate axes is shown in Fig. 2. The axial coordinate is $\mathrm{x}$, the circumferential coordinate is $\mathrm{y}$, and the thickness coordinate normal to the shell surface is $\mathrm{z}$. $\mathrm{R}$ is the radius of the cylindrical shell segment and the circumferential coordinate is replaced by $\mathrm{y}=\mathrm{R} \beta$. The displacement field for an intact cylindrical shell, according to a first-order, shear deformation theory is given by

$$
\begin{aligned}
& \mathrm{u}_{\mathrm{x}}=\mathrm{u}_{\mathrm{x}}^{0}+\mathrm{z}_{\mathrm{x}} \\
& \mathrm{u}_{\mathrm{y}}=\mathrm{u}_{\mathrm{y}}^{0}+\mathrm{z}_{\mathrm{y}} \\
& \mathrm{u}_{\mathrm{z}}=\mathrm{u}_{\mathrm{z}}^{0}
\end{aligned}
$$

$\mathrm{u}_{\mathrm{x}}, \mathrm{u}_{\mathrm{y}}, \mathrm{u}_{\mathrm{z}}$ are the displacements (in the $\mathrm{x}, \mathrm{y}$ and $\mathrm{z}$ directions, respectively) and $\psi_{\mathrm{x}}, \psi_{\mathrm{y}}$ are the rotations (about $y$ and $x$ axes, respectively), at arbitrary locations with the distance $z$ to the shell's mid-surface. $\mathrm{u}_{\mathrm{x}}^{0}, \mathrm{u}_{\mathrm{y}}^{0}, \mathrm{u}_{\mathrm{z}}^{0}$ are the mid-surface displacements of the shell in the respective directions.

For the finite element analysis of a typical cylindrical shell or panel without delamination and under axial compression, a single layer of shell elements can be employed and the corresponding buckling and post-buckling analysis can be performed. It is also possible 
to model the entire laminate using two layers of shell elements forming an upper and lower sublaminate, where the nodes are located on the mid-surfaces of the laminates. See Fig. 3a. In order to enforce compatibility along the interface, constraint equations based on equations 1 can be imposed. The following constraint equations will tie the upper and lower sublaminates in both displacements and rotations along the interface so that both sublaminates together deform like an intact single laminate.

$$
\begin{aligned}
& \mathrm{u}_{\mathrm{x}}^{1,0}-\left(\frac{\mathrm{h}_{1}}{2}\right) \psi_{\mathrm{x}}^{1}=\mathrm{u}_{\mathrm{x}}^{2,0}+\left(\frac{\mathrm{h}_{2}}{2}\right) \psi_{\mathrm{x}}^{2} \\
& \mathrm{u}_{\mathrm{y}}^{1,0}-\left(\frac{\mathrm{h}_{1}}{2}\right) \psi_{\mathrm{y}}^{1}=\mathrm{u}_{\mathrm{y}}^{2,0}+\left(\frac{\mathrm{h}_{2}}{2}\right) \psi_{\mathrm{x}}^{2} \\
& \mathrm{u}_{\mathrm{z}}^{1,0}=\mathrm{u}_{\mathrm{z}}^{2,0}
\end{aligned}
$$

The first superscripts 1 and 2 of the displacements refer to the upper and lower sublaminates, respectively, and the second superscript 0 refers to the sublaminate's midsurface. $h_{1}$ and $h_{2}$ are the thicknesses of the upper and lower sublaminates, respectively. In order to examine the accuracy of the double-layer model, an intact laminated curved panel with a stacking sequence of $[ \pm \theta / \pm \theta / \theta]_{s}$, under axial compression is analysed. The geometry and boundary conditions of the curved panel are shown in Fig.4, where the angle subtended by the arclength is $\pi$ radians. The panel is $1.524 \mathrm{~m}$ long with a radius of $0.1524 \mathrm{~m}$ and is considered to be simply supported on its edges. Each ply in the $[ \pm \theta / \pm \theta / \theta]_{\mathrm{s}}$ laminate is $0.305 \mathrm{~mm}$ thick with material properties of $\mathrm{E}_{11}=94.8 \mathrm{GPa}, \mathrm{E}_{22}=7.1 \mathrm{GPa}$, $\mathrm{G}_{12}=\mathrm{G}_{23}=\mathrm{G}_{13}=2.9 \mathrm{GPa}$ and $v_{12}=0.25$. Therefore, the geometric parameters of the panel are $\mathrm{R} / \mathrm{t}=50$ and $\mathrm{L} / \mathrm{R}=10$.

Jaunky et al [12] analysed this panel using different shell theories such as Sanders-Koiter [25-26], Love [27] and Donnell [28]. They predicted that Donnell's theory could be in error for some lamination schemes and geometrical parameters. The results of SandersKoiter and Love were almost identical. The buckling loads for the curved panel for various winding angles $\left(\theta=0^{\circ}, 10^{\circ}, 20^{\circ}, 30^{\circ}, 40^{\circ}\right.$ and $\left.90^{\circ}\right)$ obtained using the Sanders-Koiter shell theory are shown in Fig. 5. 
In the present study, three different FE models are employed for the analysis of the above intact panel under axial compression. The constructed FE models are as follows: i) a single layer of shell elements, ii) two layers of shell elements split between layers 5 and 6 $\left(h_{1} / t=0.5\right)$ and iii) two layers of shell elements split between layers 3 and $4\left(h_{1} / t=0.3\right.$

). The split shells are joined using the constraint equations based on equations 2 . The finite element results are also shown in Fig.5. It can be seen that the double-layer model gives satisfactory results for the laminated curved panel under compression. $30 \times 30$ quadratic quadrilateral shell elements, designated S8R in ABAQUS [29], are employed for the modelling of each layer.

For a delaminated cylinder, the double-layer model can be employed where in areas of delamination the constraint equations will be replaced by contact elements between the corresponding nodes of the upper and lower sublaminates. Contact elements will prevent the interpenetration of the nodes of the two cylindrical layers in the delamination zone. Interpenetration would neglect the behaviour of real laminates and result in incorrect estimations of the critical load. Fig.3b Shows a close-up view of the double-layer FE model which can be used for the analysis of delaminated cylindrical shells or panels.

In comparison with the three-dimensional finite elements, the double-layer model can effectively reduce the computational time and capacity. However, the disadvantage of the double-layer model is that two layers of shell elements are required for both intact and delaminated regions of the shell.

In order to reduce the computational time and capacity for the same level of accuracy, in the present study combined double-layer and single-layer of shell elements are employed. Fig.6 shows the proposed FE model for investigation of effects of delaminations on the critical buckling loads of cylindrical shells and panels. The intact regions will be represented by a single layer of shell elements, whereas the delaminated regions will be modelled by upper and lower sublaminates that are connected by contact elements, designated GAP in ABAQUS. For the interface region a modified version of the sublaminate connection method, based on equations 1 , will be employed. Therefore, also 
the rotations $\left(\psi_{\mathrm{x}}, \psi_{\mathrm{y}}, \psi_{\mathrm{z}}\right)$ of all the nodes of the stacked layers at the transition border are coupled in addition to the displacements $\left(\mathrm{u}_{\mathrm{x}}, \mathrm{u}_{\mathrm{y}}, \mathrm{u}_{\mathrm{z}}\right)$. Thus, the coupling between the midsurfaces of the sublaminates of the damaged and the mid-surface of the laminate of the intact area is described by the following set of equations,

$$
\begin{aligned}
& \mathrm{u}_{\mathrm{x}}^{1,0}-\left(\frac{\mathrm{h}_{1}}{2}\right) \psi_{\mathrm{x}}^{1}=\mathrm{u}_{\mathrm{x}}^{2,0}+\left(\frac{\mathrm{h}_{2}}{2}\right) \psi_{\mathrm{x}}^{2}=\mathrm{u}_{\mathrm{x}}^{0} \\
& \mathrm{u}_{\mathrm{y}}^{1,0}-\left(\frac{\mathrm{h}_{1}}{2}\right) \psi_{\mathrm{y}}^{1}=\mathrm{u}_{\mathrm{y}}^{2,0}+\left(\frac{\mathrm{h}_{2}}{2}\right) \psi_{\mathrm{y}}^{2}=\mathrm{u}_{\mathrm{y}}^{0} \\
& \mathrm{u}_{\mathrm{z}}^{1,0}=\mathrm{u}_{\mathrm{z}}^{2,0}=\mathrm{u}_{\mathrm{z}}^{0} \\
& \psi_{\mathrm{x}}^{1}=\psi_{\mathrm{x}}^{2}=\psi_{\mathrm{x}}^{0} \\
& \psi_{\mathrm{y}}^{1}=\psi_{\mathrm{y}}^{2}=\psi_{\mathrm{y}}^{0} \\
& \psi_{\mathrm{z}}^{1}=\psi_{\mathrm{z}}^{2}=\psi_{\mathrm{z}}^{0}
\end{aligned}
$$

In a study by Tafreshi and Oswald [11], combined single-layer and double-layer of shell elements were employed to investigate the global buckling behaviour and local damage propagation of composite flat plates containing embedded delaminations. Some of the results were compared with the corresponding experimental results. It was shown that in comparison with the three-dimensional modelling the combined modelling can effectively reduce the computational time and capacity for the same level of accuracy.

\section{CYLINDRICAL SHELL WITH DELAMINATION ALONG THE ENTIRE CIRCUMFERENCE}

Simitses et al [19-20] analytically predicted delamination buckling of cylindrical shells and panels. The load cases considered in their study were uniform axial compression and uniform external pressure, applied individually. In order to ease the mathematical modelling, they kept the models as simple as possible. For example, in the axial compression case, the delamination extended along the entire circumference of the cylindrical shell. In the case of external pressure, cylindrical shells and panels with longitudinal delamination over the entire length were considered. For both cases they did not account for the contact between delaminated layers during buckling. 
An example of a cylindrical shell made of isotropic material with clamped ends under axial compression, similar to the model employed by Simitses et al [19], is presented here to validate the proposed FE modelling approach. The delamination is located symmetrically with respect to both ends of the shell and it spans the entire circumference. See Fig. 1b. The dimensions of the shell are such that $L / R=5$ and $R / t=30$. The numerical results of variation of critical load with delamination length and delamination thickness, obtained using the present method, are compared with those obtained by Simitses et al [19-20], as shown in Fig.7. The critical loads are normalized with respect to the critical load of an intact cylinder.

It is shown that that although Simitses et al [19-20] did not account for the contact, between delaminated layers during buckling, their results look reasonable. For the delamination thicknesses of $\overline{\mathrm{h}}=0.3$ and 0.5 , with delamination length of $\overline{\mathrm{a}}>0.04$, the buckling load will increase when considering the effect of contact in the buckling mode. For the delamination thickness of $\overline{\mathrm{h}}=0.1$, with delamination length of $\overline{\mathrm{a}}>0.04$, the effect of contact in the buckling mode is almost negligible. This figure also shows that, for very small values of the delamination length $(\overline{\mathrm{a}}<0.01)$, regardless of the delamination thickness and also the effect of contact, the delamination has no significant effect on the critical loads. For the delamination length of $(0.01<\overline{\mathrm{a}}<0.04)$, the buckling load will decrease when considering the effect of contact in the buckling mode.

Some parametric studies are also performed to investigate the effect of material properties. Similar results are obtained for two composite cylindrical shells made of graphite-epoxy and kevlar-epoxy laminates. The cylinders have the same geometry and boundary conditions as the isotropic cylinder studied earlier. The cross-ply laminates have the stacking sequence of $\left[0^{\circ} / 90^{\circ} / 0^{\circ}\right]_{10 \mathrm{~T}}$. The lamina engineering constants for the graphite-epoxy and kevlar-epoxy composites are shown in Table 1.

Fig. 8 compares the variations of critical load with delamination length and delamination thickness for the isotropic, graphite-epoxy and kevlar-epoxy cylinders. The presented results include two delamination thicknesses of $\bar{h}=0.5$ and 0.3 . The results for the 
delamination thickness of $\bar{h}=0.1$ are obtained but are not presented. However, for $\bar{h}$ $=0.1$, the trends of the variation of buckling loads with respect to the delamination length in the laminated and isotropic cylindrical shells are similar. See Fig. 7.

The analysis of the selected materials shows that for very small values of the delamination length $(\overline{\mathrm{a}}<0.01)$, the delamination has no significant effect on the critical loads, regardless of the delamination thickness and material properties. For the delamination length of $\bar{a}>0.01$, when delamination is located near the free surface of the shell $(\overline{\mathrm{h}}=0.1)$, regardless of the material property, a sharp drop in the critical load is noticed. For $\overline{\mathrm{h}}=0.1$ and $\overline{\mathrm{a}}>0.01$, the normalized critical buckling loads for the selected materials vary between $0.14-0.23$.

For the isotropic cylindrical shell, with delamination length of $\bar{a}>0.04$, the critical buckling load decreases as the delamination through thickness position decreases. For the composite cylinders, except when delamination is located near the free surface, the critical buckling load decreases as the delamination through thickness position increases. It can be said that in the composite cylinders, for $0.3<\overline{\mathrm{h}}<0.5$, the lowest critical buckling load occurs when delamination is located at mid-surface.

Next, the buckling behaviour of the two laminates is compared. As seen from Fig. 8, for the same delamination thickness, graphite-epoxy with a higher longitudinal-to-transverse modulus ratio $\left(\mathrm{E}_{\mathrm{L}} / \mathrm{E}_{\mathrm{T}}=40\right)$ and a higher transverse-to-shear modulus ratio $\left(\mathrm{E}_{\mathrm{T}} / \mathrm{G}_{\mathrm{LT}}=2.0\right)$ has a higher critical buckling load. For a certain delamination thickness, when $\bar{a}>0.4$, the critical buckling load is almost independent of the delamination length and material properties, as shown in Fig. 8.

Fig. 9 shows the first buckling mode of the graphite-epoxy cylindrical shell without any delamination. Fig. 10 shows the first buckling mode of the delaminated graphite-epoxy cylinder, with the delamination length of $\bar{a}=0.125$, extended along its entire circumference, for $\overline{\mathrm{h}}=0.5,0.3$ and 0.1 , respectively. 


\section{CYLINDRICAL SHELL WITH A RECTANGULAR DELAMINATION}

Results are generated for a cylindrical shell with a rectangular delamination. See Fig. 1a. The dimensions and boundary conditions of the cylindrical shell are the same as the cylinder studied in section 3 of this $\operatorname{paper}(\mathrm{R} / \mathrm{t}=30, \mathrm{~L} / \mathrm{R}=5)$. The analysis has been carried out for three different materials, isotropic, graphite-epoxy and kevlar-epoxy. The crossply laminates have the stacking sequence of $\left[0^{\circ} / 90^{\circ} / 0^{\circ}\right]_{10 \mathrm{~T}}$. The results are computed for different delamination sizes and thicknesses. The delamination length $(\bar{a})$ and delamination width $(\alpha)$ vary as $0.04<\bar{a}<0.42$ and $\pi / 12<\alpha<5 \pi / 12$, respectively. The delamination thicknesses considered are, $\overline{\mathrm{h}}=0.5,0.3$ and 0.1 . Figures 11-13 show the effect of delamination size and thickness on the critical buckling loads for the isotropic, graphite-epoxy and kevlar-epoxy cylinders, respectively. The following observations are made from this study.

Regardless of the material properties, when delamination is located near the free surface of the shell $(\bar{h}=0.1)$, the critical buckling load mainly depends on the delamination width $(\alpha)$ and almost independent of the delamination length. However, in the composite cylindrical shells, for the delamination thickness of $\bar{h}=0.1$ and delamination width of $\alpha<\pi / 4$, the delamination has no significant effect on the critical buckling loads. See Figs. $11 \mathrm{c}, 12 \mathrm{c}$ and $13 \mathrm{c}$.

In the isotropic cylindrical shell, for the delamination thickness of $\overline{\mathrm{h}}=0.5$ and delamination size of $(\bar{a}>0.1, \alpha>\pi / 4)$, and also for the delamination thickness of $\bar{h}=0.3$ and delamination size of $(\bar{a}>0.1, \alpha>\pi / 2)$, the critical buckling load is virtually unaffected by the delamination. For the delamination thickness of $\overline{\mathrm{h}}=0.5$ and delamination size of ( $\bar{a}<0.1, \alpha<\pi / 4)$, and also for the delamination thickness of $\overline{\mathrm{h}}=0.3$ and delamination size of $(\bar{a}<0.1, \alpha<\pi / 2)$, the critical buckling load mainly depends on the delamination width. See Figs. 11a and 11b. It can be said that for the aforementioned sizes of delamination, for two models with equal areas of delaminations, the delamination with higher width creates a lower buckling load. 
In the composite cylindrical shells, for the delamination thickness of $\overline{\mathrm{h}}=0.5$, the critical buckling load gradually decreases with the increase of the delamination area. As shown in Figs. 12a and 13a, delamination length and delamination width have almost the same effect in reducing the critical buckling load. For the delamination thickness of $\bar{h}=0.3$, for very small values of the delamination area, when $\bar{a}<0.1$ and $\alpha<\pi / 6$, the delamination has no significant effect on the critical loads. When $\bar{a}>0.1$ and, $\alpha>\pi / 6$, there is a gradual drop in the critical buckling load with respect to the increase of the delamination area.

The buckling behaviour of the two laminates is also compared. It can be observed that for the same delamination area, graphite-epoxy with a higher longitudinal-to-transverse modulus ratio $\left(\mathrm{E}_{\mathrm{L}} / \mathrm{E}_{\mathrm{T}}=40\right)$ and a higher transverse-to-shear modulus ratio $\left(\mathrm{E}_{\mathrm{T}} / \mathrm{G}_{\mathrm{LT}}=2.0\right)$ has a higher critical buckling load. For both composite shells, except when the delamination is located near the free surface, the higher the delamination thickness is the lower the critical buckling load is. It can be said that the lowest critical buckling load occurs when the delamination is located at the laminate's mid-surface. However, for very large delamination area, when $\bar{a}>0.4$ and, $\alpha>5 \pi / 6$, the critical buckling load is almost independent of the delamination size and material properties and only depends on the delamination thickness.

Figure 14 shows the first buckling mode of the graphite-epoxy cylindrical shell with a rectangular delamination of $(\bar{a}=0.125, \alpha=\pi / 4)$ and delamination thicknesses of $\bar{h}=0.5$, 0.3 and 0.1 , respectively. Depending on the size and through the thickness position of delaminations and also material properties of the cylindrical shell, three different modes of buckling behaviour occur. These three modes are referred to as the local, global and mixed. The local mode occurs when the delamination is near the free surface of the laminate and the area of the delamination is large. The global mode occurs when the delamination has a small area and is deeper within the laminate. The mixed mode is a combination of local and global buckling.

The number of shell elements, designated S8R in ABAQUS, which were used for the modelling of the cylindrical shells vary between 2500-4600. The lowest size of the 
delamination area considered in this study had the delamination length of $\overline{\mathrm{a}}=0.01$ and delamination width of $\alpha=\pi / 24$. The analysis of cylinders with lower delamination areas was at the expense of the increase in the computational time and space. However, using the present method, the double layer of shell elements is only used in the delaminated region. On the other hand, as mentioned earlier for very small delamination areas, regardless of the delamination thickness, the presence of delamination does not appreciably alter the critical load of a perfect geometry.

\section{CONCLUDING REMARKS}

Combined single-layer and double-layer of shell elements are employed to study the delamination buckling of isotropic and composite cylindrical shells subject to compressive axial load. It is shown that the present method is highly efficient and accurate. Results show that for very small values of the delamination area, the presence of delamination has no significant effect on the critical loads. For large delamination area, especially when the delaminated layer is closer to the free surface of the laminate, the critical load is small. It is also observed that ignoring the effect of contact between the delaminated layers can lead to incorrect estimations of the critical buckling loads.

It must be noted that the FE modelling presented in this paper can also be used to investigate multiple through-the-width delaminations in composite laminated cylinders. Therefore, multi-layer of shell elements must be employed in the delaminated region and contact elements must be placed between the delaminated layers to prevent overlapping of the layers.

\section{REFERENCES}

1. Tafreshi, A., "Shape optimization of anisotropic structures using the boundary element method", Journal of Strain Analysis, 2003;3(38):219-232 
2. Tafreshi, A., "Shape design sensitivity analysis of $2 \mathrm{D}$ anisotropic structures using the boundary element method", Engineering Analysis with Boundary Elements, 2002;26: 237-251

3. Bolotin, V.V., "Delamination in composite structures: its origin, buckling, growth and stability", Composites: Part B, 1996;27B:129-145

4. Klug, J., Wu, X.X. and Sun, C.T., "Efficient modelling of postbuckling delamination growth in composite laminates using plate elements", AIAA J., 1996;34(1):178-184

5. Whitcomb, J.D., "Three-dimensional analysis of a postbuckled embedded delamination”, Journal of Composite Materials, 1989;23(9):862-889

6. Pavier M.J. and Clarke, M.P., "A specialised composite plate element for problems of delamination buckling and growth", Composite Structures, 1996;34:43-53

7. Chattopadhyay, A. and $\mathrm{Gu}, \mathrm{H}$., "New higher order plate theory in modelling delamination buckling of composite laminates", AIAA J, 1994;32(8):1709-1716

8. Chai, G.B., Banks, W.M. and Rhodes J., "Experimental study on the buckling and postbuckling of carbon fibre composite panels with and without interply disbonds", Proceedings of the Institution of Mechanical Engineers: Design in Composite Materials, Mechanical Engineering Publications; 1989:69-85

9. Chai, H., Babcock, C.A. and Knauss, W.G., "One dimensional modelling of failure in laminated plates by delamination buckling”, International Journal of Solids and Structures, 1981;Vol. 17(11):1069-83

10. $\mathrm{Hu}, \mathrm{N}$.,'Buckling analysis of delaminated laminates with consideration of contact in buckling mode", International Journal For Numerical Methods in Engineering”, $1999 ; 44: 1457-1479$

11. Tafreshi, A. and Oswald T., "Global buckling behaviour and local damage propagation in composite plates with embedded delaminations", International Journal of Pressure Vessels and Piping, 2003;80(1):9-20,

12. Jaunky, N., Knight N.F. Jr, "An assessment of shell theories for buckling of circular cylindrical laminated composite panels loaded in axial compression", International Journal of Solids and Structures, 1999;36:3799-3820 
13. Jaunky, N., Knight, N.F. Jr and Ambur, D.R., "Buckling analysis of anisotropic variable-curvature panels and shells", Composite Structures, 1999;43:321-329

14. Chaplin, C.P. and Palazotto, A.N., "The collapse of composite cylindrical panels with various thickness using finite element analysis", Computers and Structures, 1996;60(5):797-815,

15. Rezeepazhand, J., Simitses, G.J. and Starnes, J.H. Jr, "Scale models for laminated cylindrical shells subjected to axial compression", Composite Structures, $1996 ; 34: 371-379$

16. Tafreshi, A., "Buckling and post-buckling analysis of composite cylindrical shells with cutouts subjected to internal pressure and axial compression loads" International Journal of Pressure Vessels and Piping, 2002;79(5):351-359

17. Tafreshi, A.,"Numerical analysis of thin torispherical end closures", International Journal of Pressure Vessels and Piping, 1997;71:77-88

18. Tafreshi, A. and Thorpe, T.E., "Effects of local departures from nominal dimensions on stresses in thin torispherical end-closures", Journal of Strain Analysis, 1996;31(4): 315-324

19. Simitses, G.J., Chen, Z.Q. and Sallam S., "Delamination buckling of cylindrical laminates", Thin-walled Structures, 1991;11:25-41

20. Sallam, S. and Simitses, G.J., "Delamination buckling of cylindrical shells under axial compression", Composite Structures, 1987;7:83-101

21. Short,G.J. Guild, F.J. and Pavier,M.J., ’'Delaminations in flat and curved composite laminates subjected to compressive load”, Composite Structures, 2002; 58:249-258

22. Kutlu, Z. and Chang, F.K., "Composite panels containing multiple through-thewidth delaminations and subjected to compression. Part I: analysis, Composite Structures, 1995;31:273-296

23. Kutlu, Z. and Chang, F.K., "Composite panels containing multiple through-thewidth delaminations and subjected to compression. Part II: experiments \& verification, Composite Structures, 1995;31:297-314

24. Naganarayana, B.P., Huang, B.Z. and Atluri S.N., "Multidomain modelling and analysis of delaminated stiffened composite shells", AIAA J., 1996;34(9):1894-904 
25. Sanders, Jr, J.L., "An improved first approximation theory for thin shells", NASA Report R-24, 1959

26. Koiter, W.T., "A consistent first approximation in general theory of thin elastic shells", The theory of thin elastic shells, Proceedings IUTAM Symposium, Delft, North-Holland, Amsterdam, The Netherlands, 1959:12-33

27. Love, A.E.H., "A treatise on the mathematical theory of elasticity", 4th ed., Dover Publication, New York, 1927

28. Loo, T.T., "An extension of Donnell's equation for circular cylindrical shell" Journal of Aeronautical Sciences 1957;24:390-1

29. ABAQUS User's Manual, Version 6.3, Hibbit, Karlson and Sorenson, Inc. 19992002 


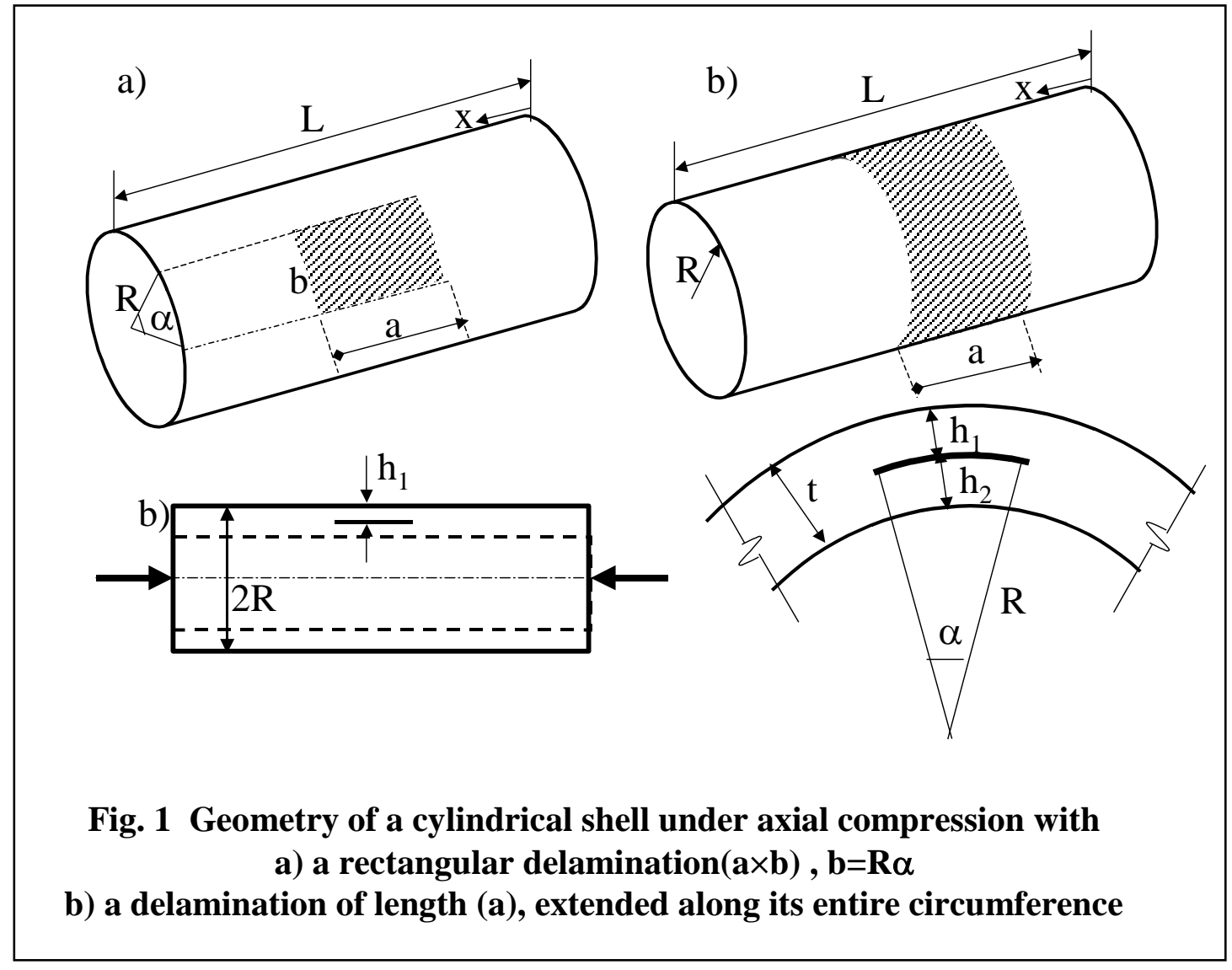




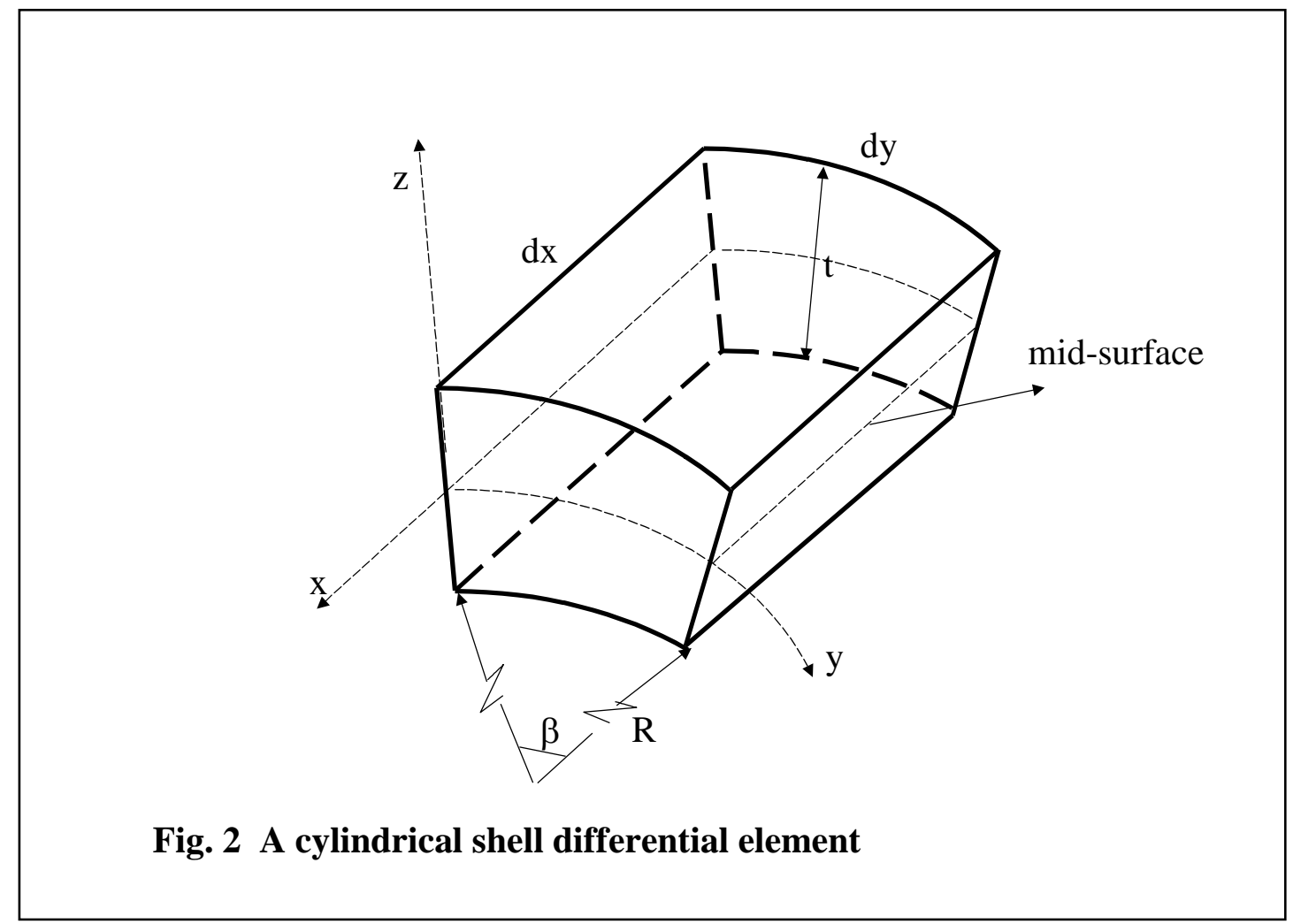




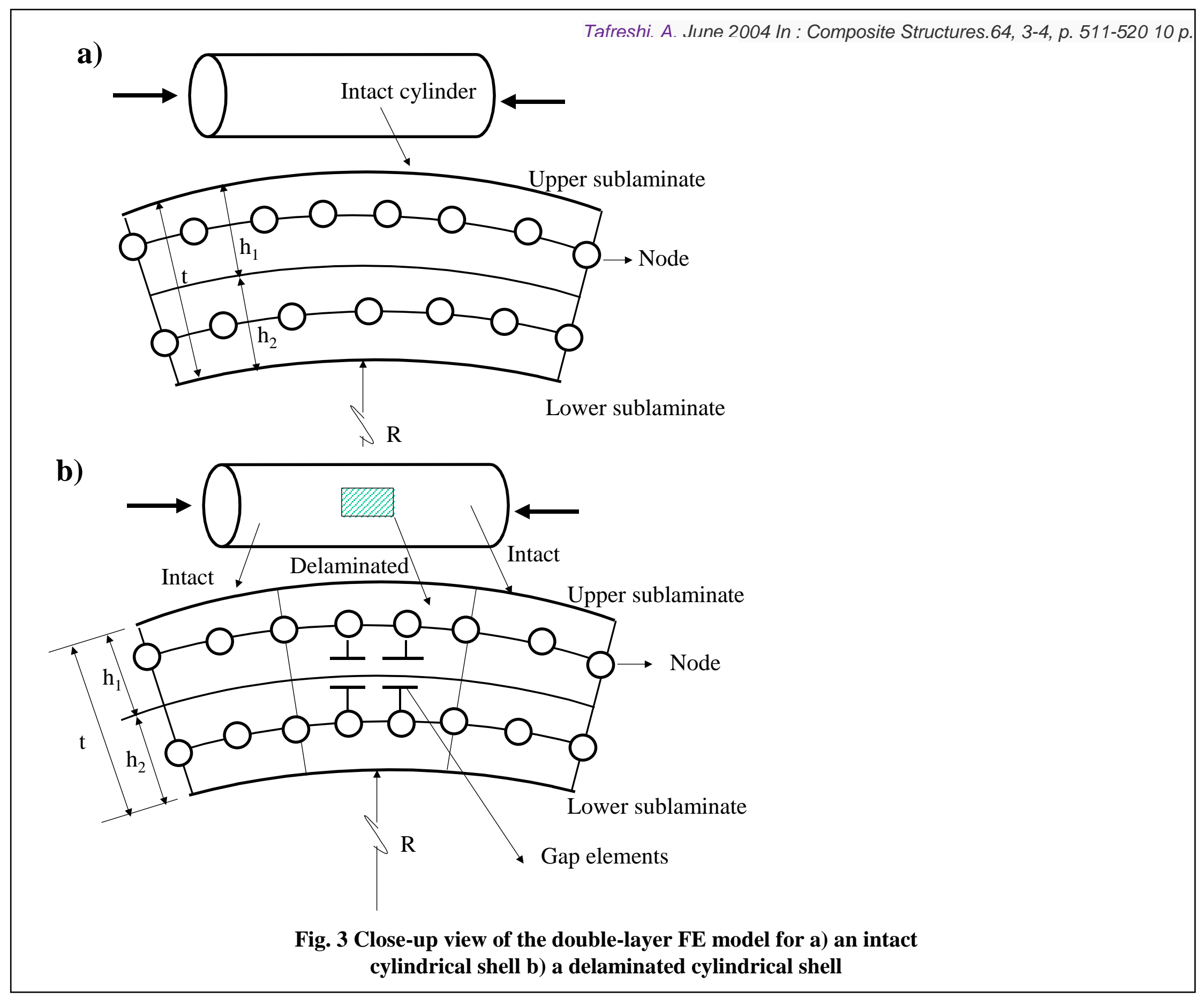




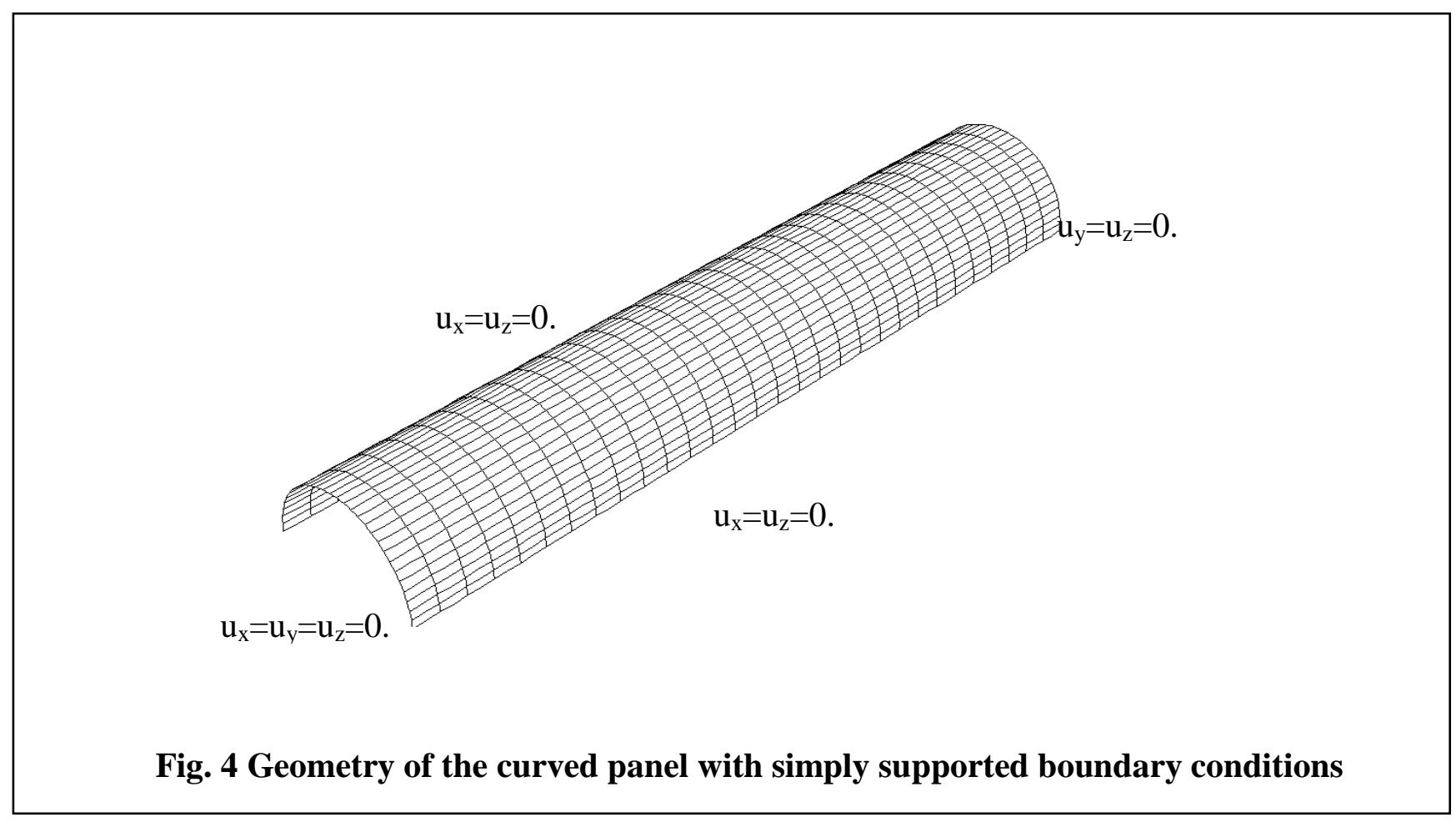




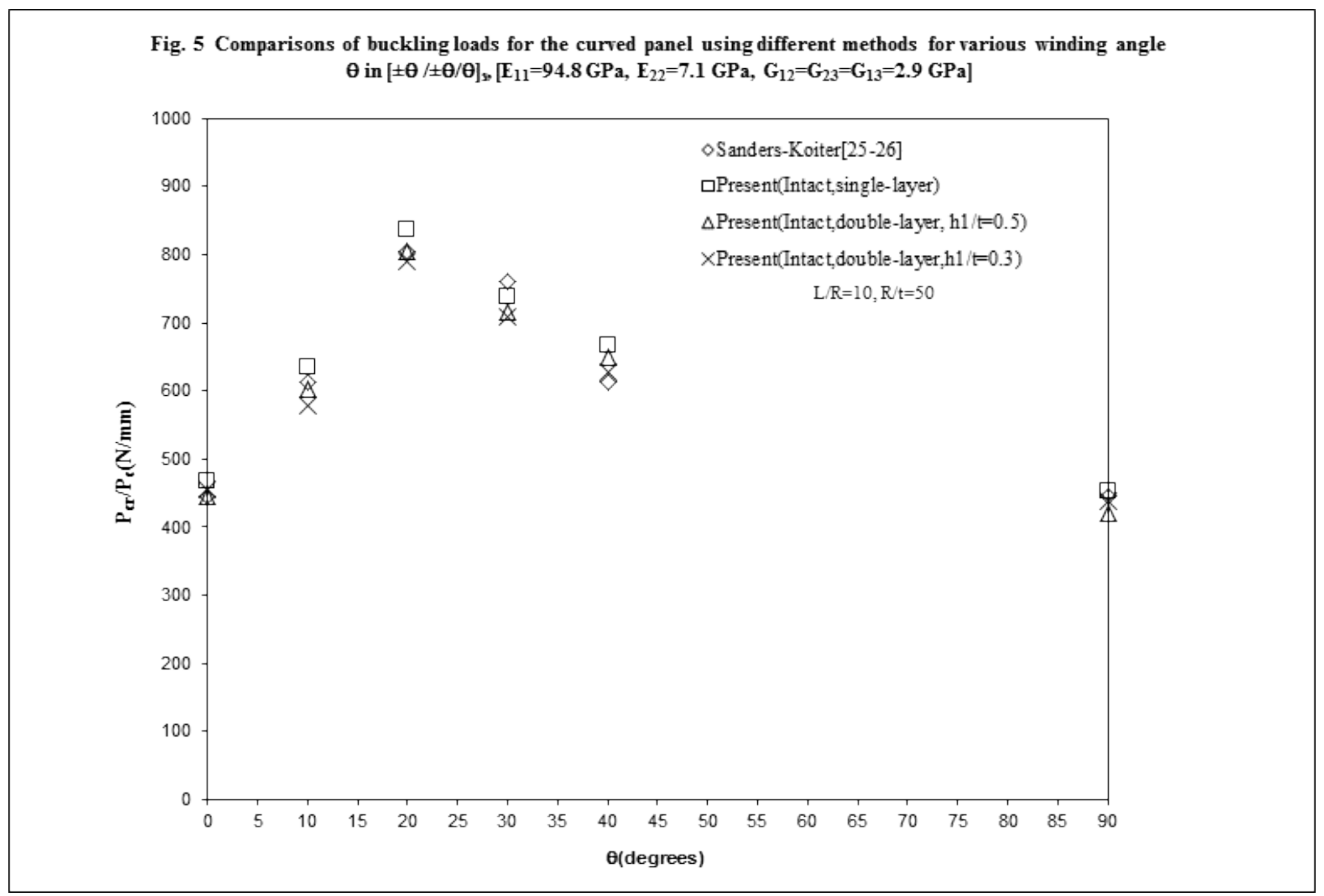




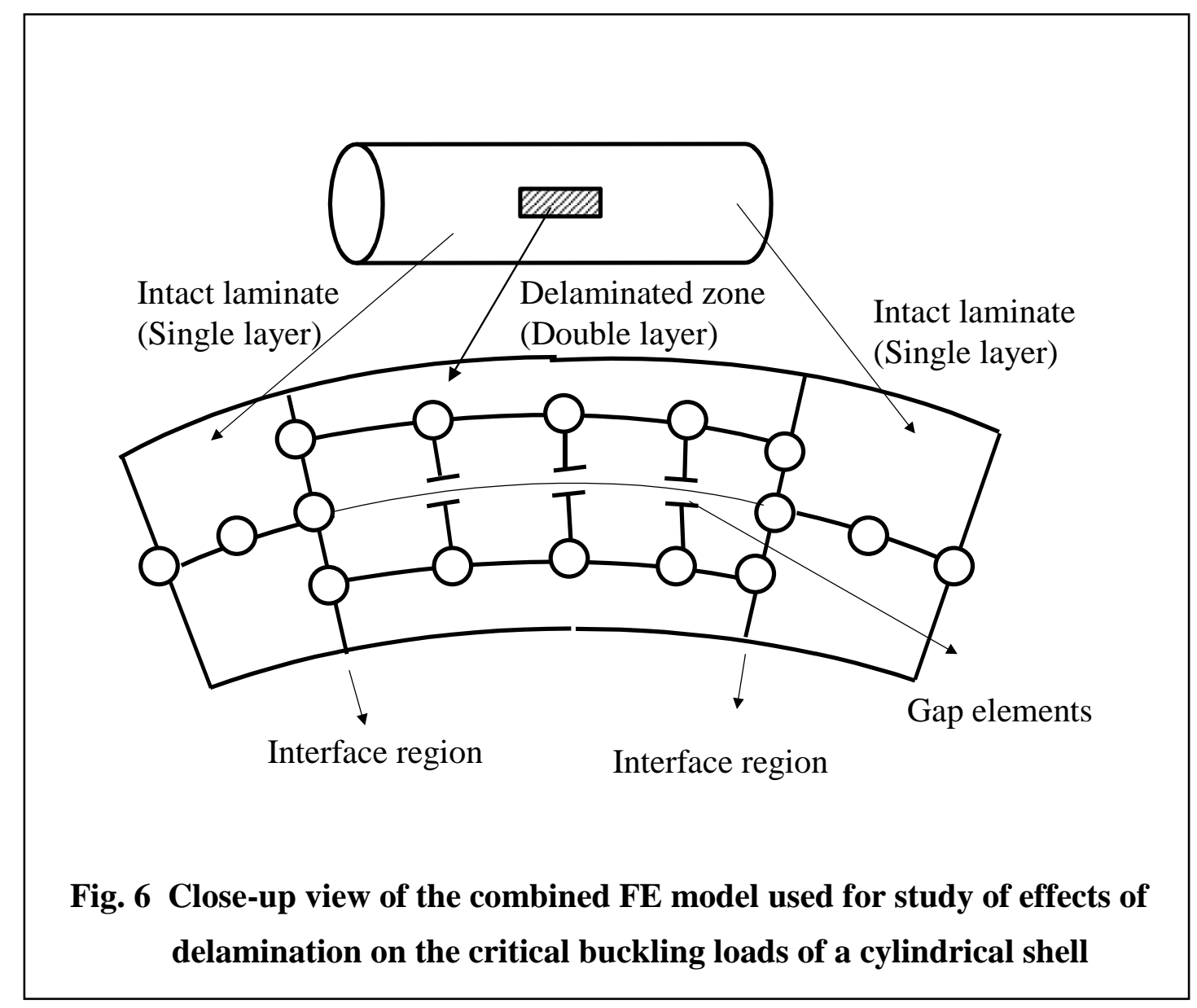




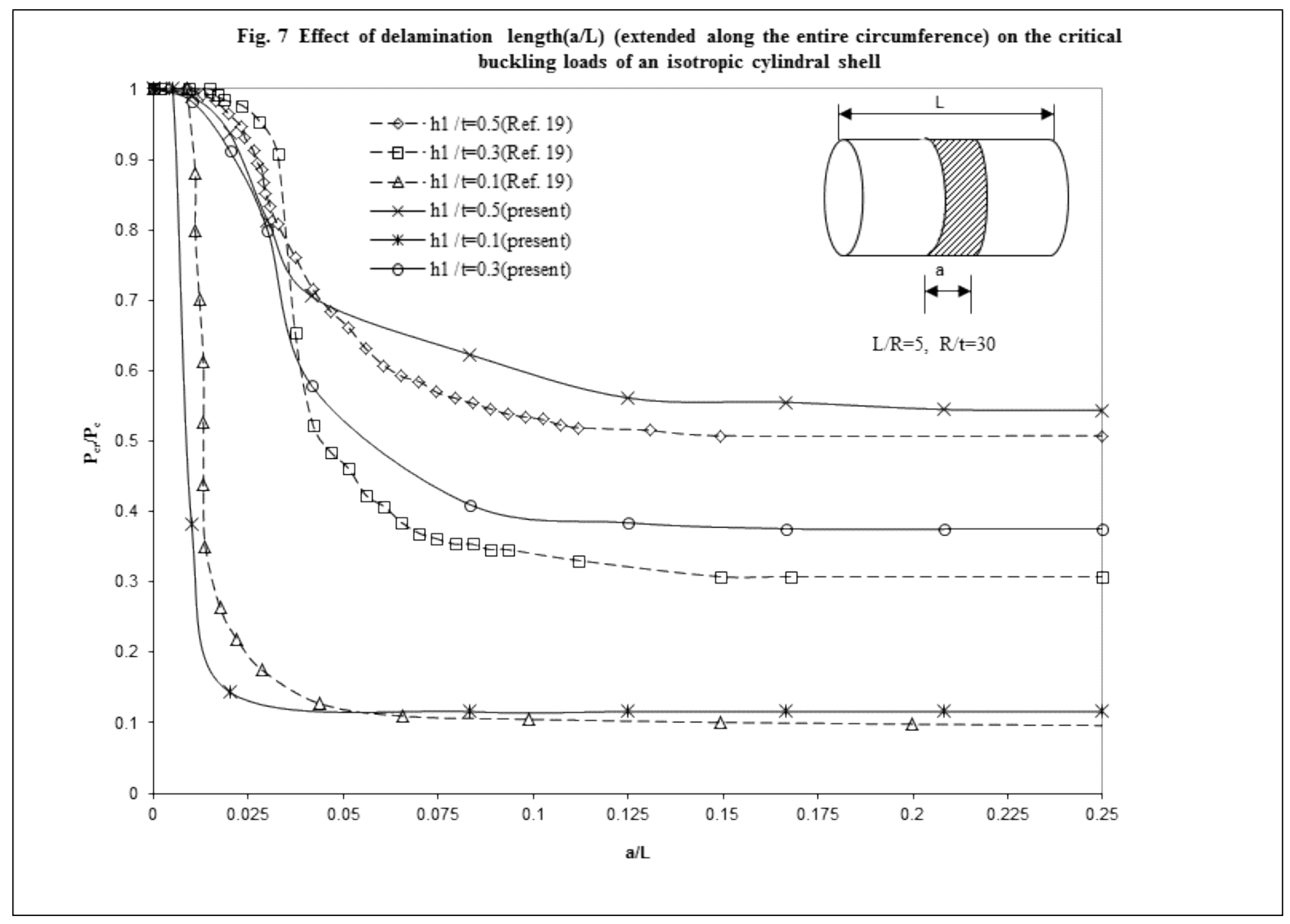


Fig. 8 Effect of delamination length $(\mathrm{a} / \mathrm{L})$ (extended along the entire circumference), on the critical buckling loads of isotropic, graphite-epoxy and kevlar-epoxy cylindrical shells

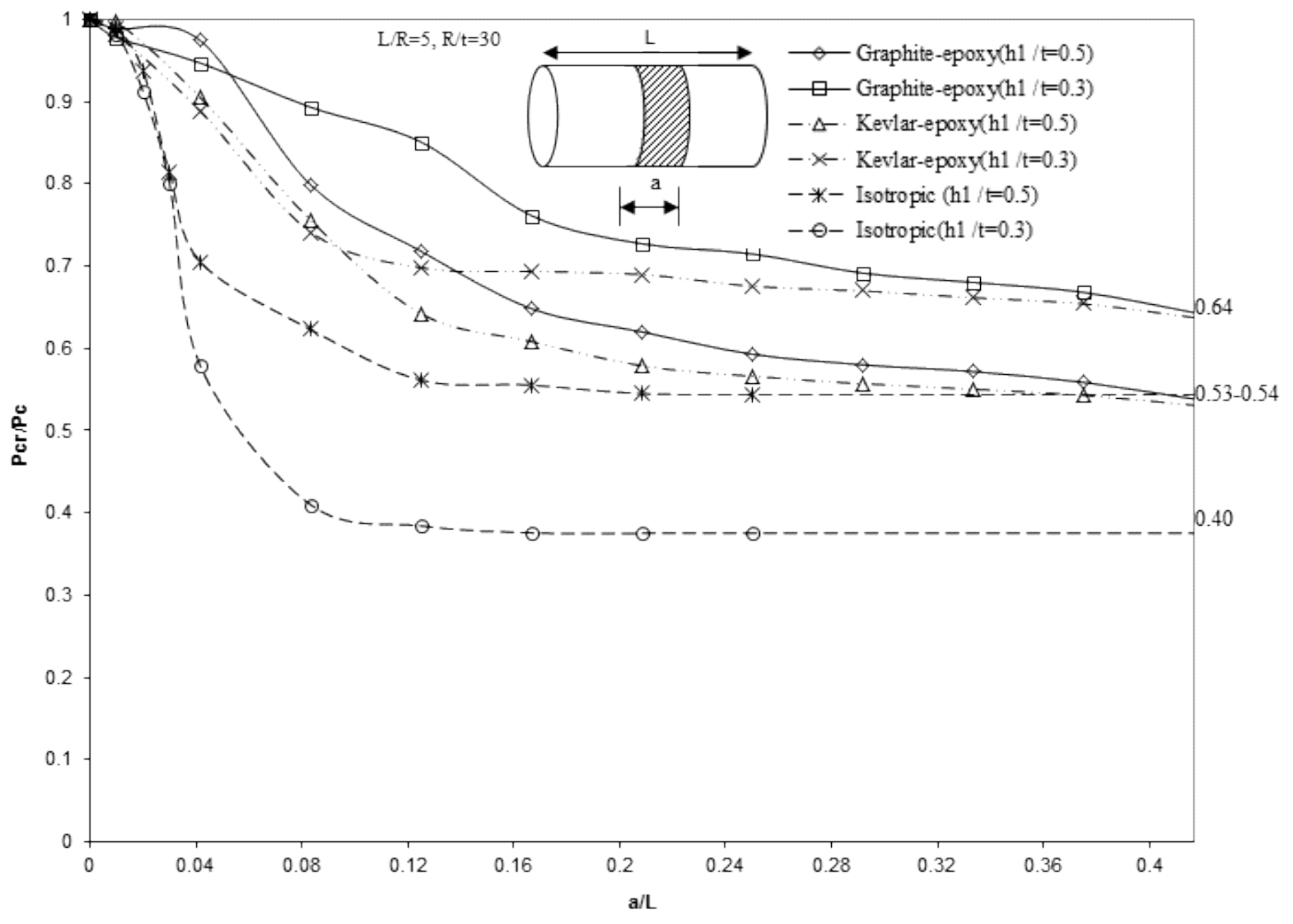




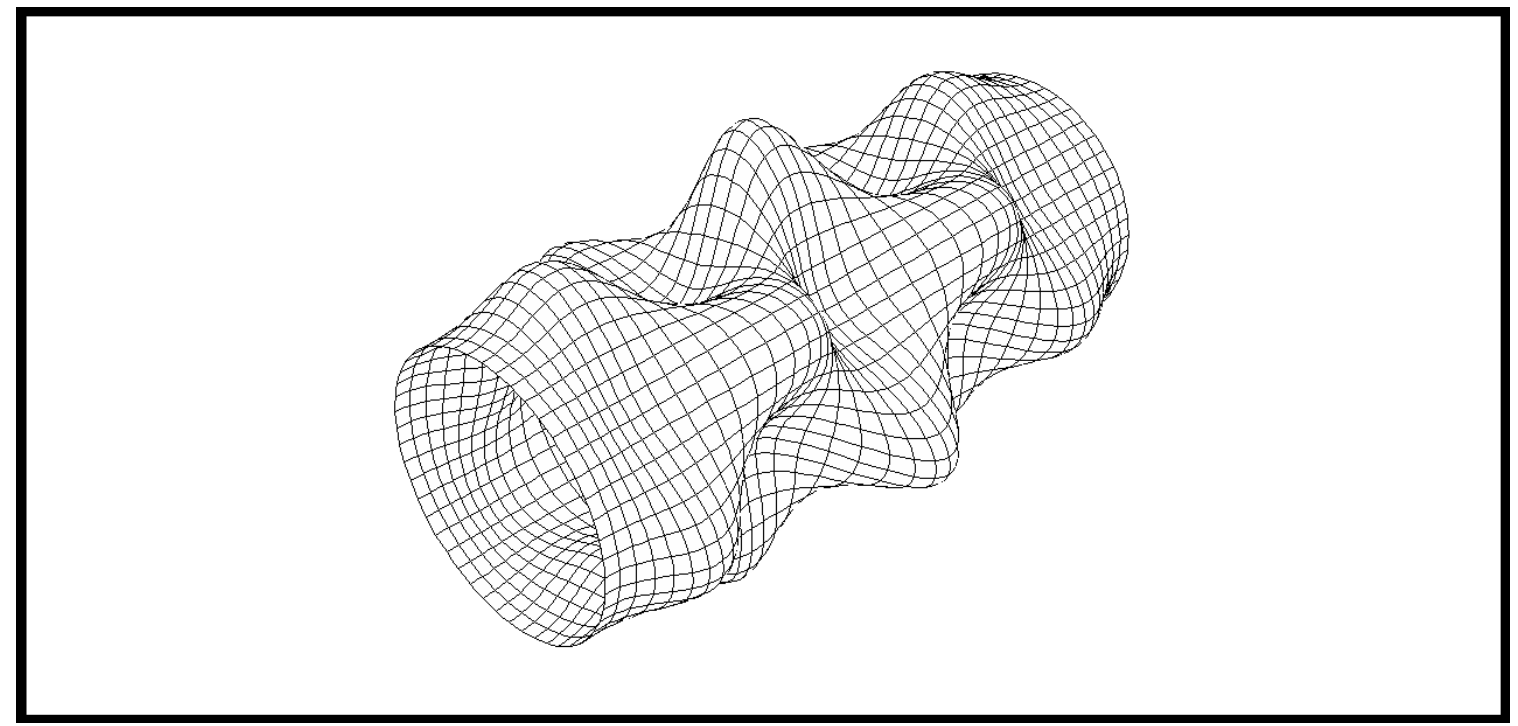

Fig. 9 First buckling mode of an intact graphite-epoxy cylindrical shell $(\mathrm{L} / \mathrm{R}=5, \mathrm{R} / \mathrm{t}=30)$ 


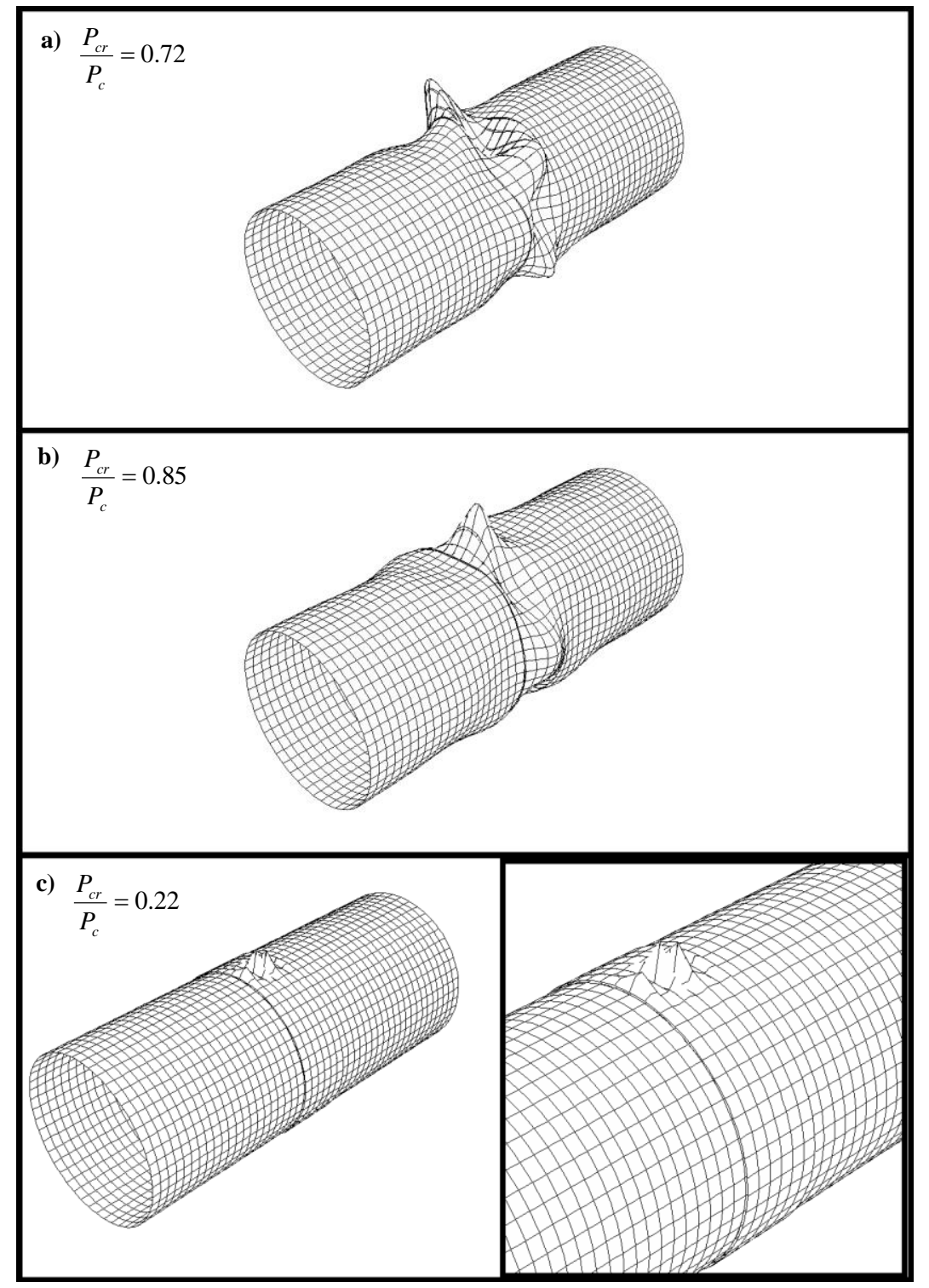

Fig. 10 First buckling mode of a delaminated graphite-epoxy cylindrical shell

$(L / R=5, R / t=30)$ with the delamination length of $a / L=0.125$ (extended along its entire

circumference) and delamination thickness of a) $h_{1} / t=0.5 \quad$ b) $h_{1} / t=0.3 \quad$ c) $h_{1} / t=0.1$ 


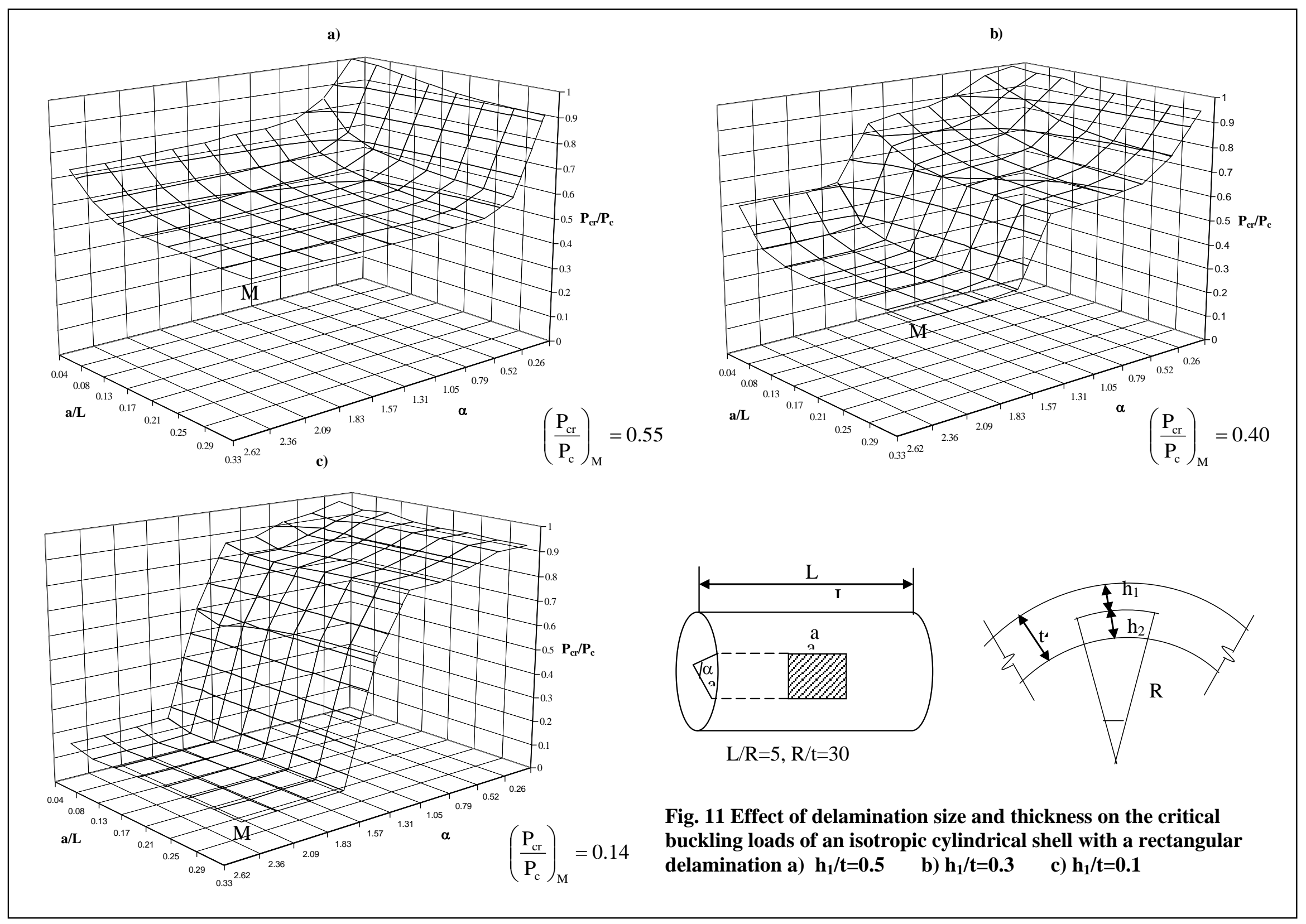




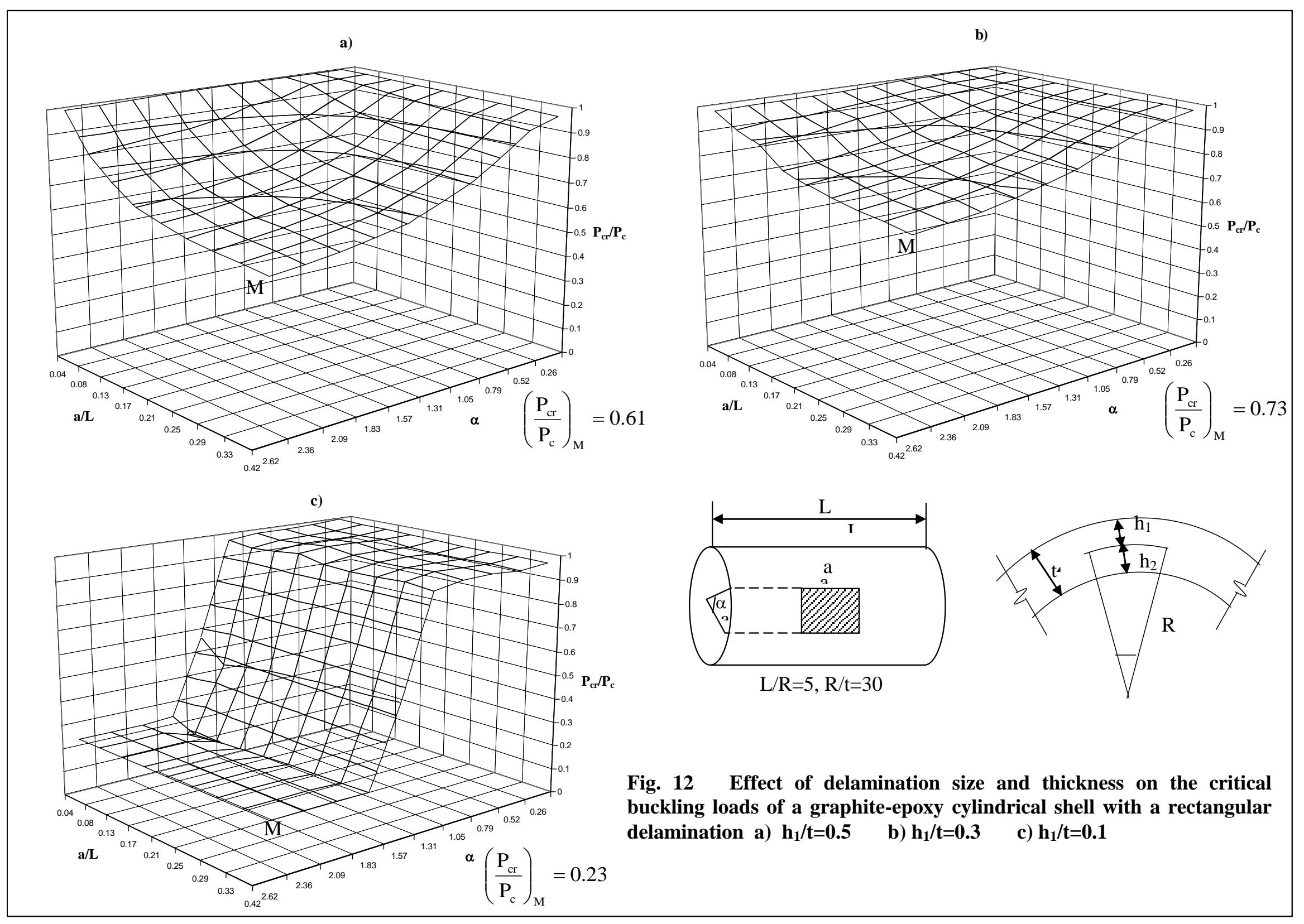




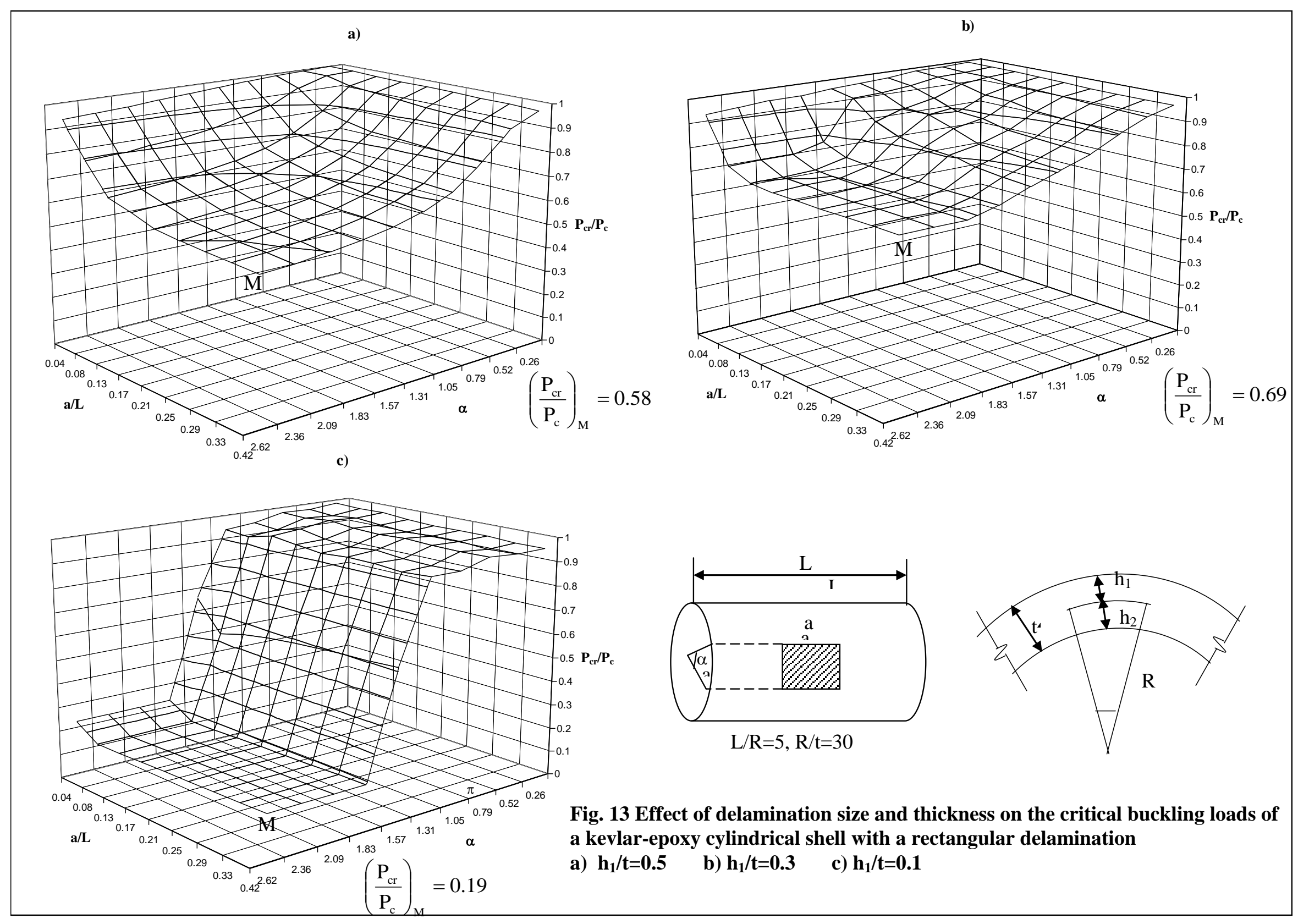


Tafreshi, A. June 2004 In : Composite Structures.64, 3-4, p. 511-520 10 p.

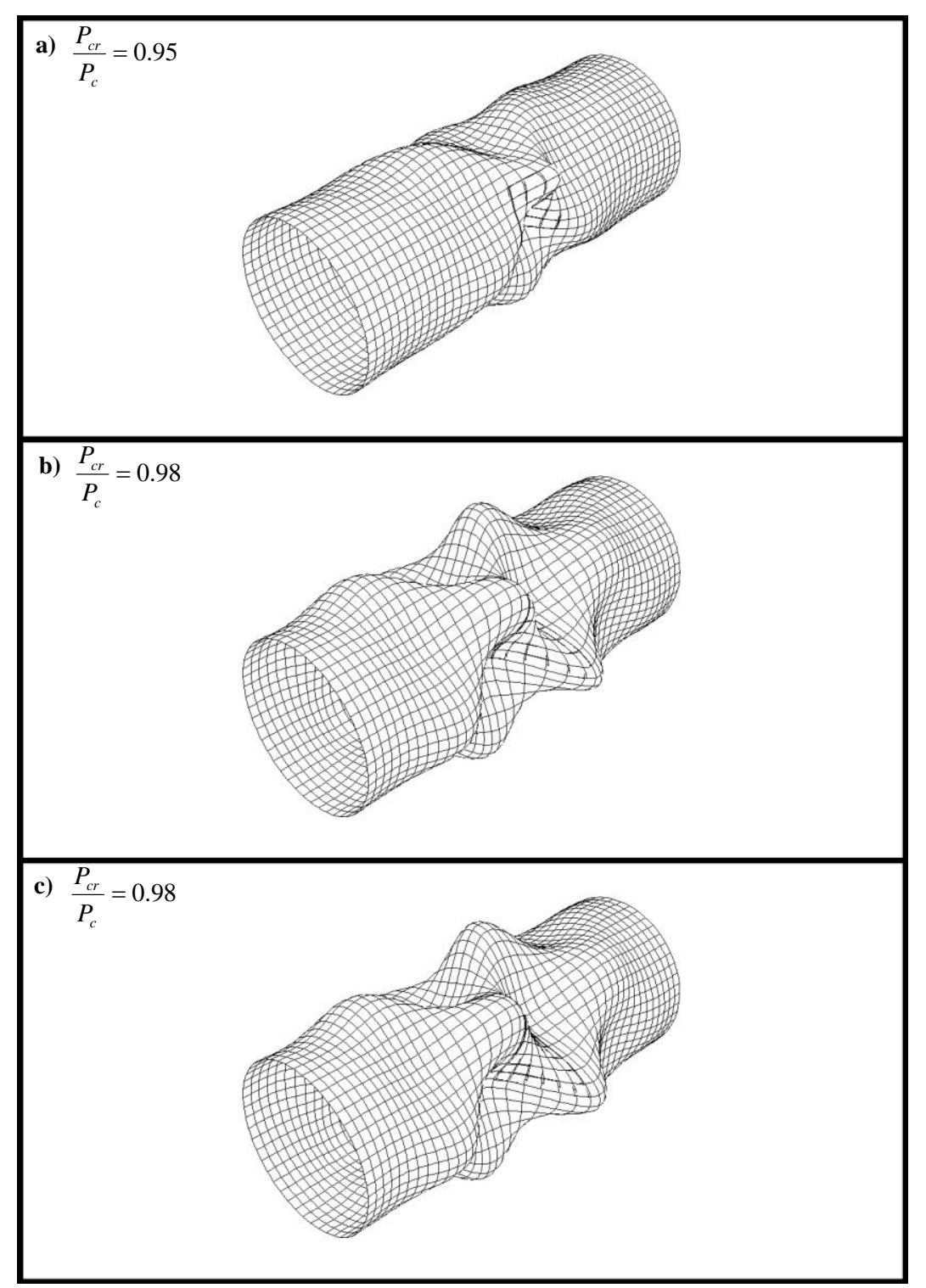

Fig. 14 First buckling mode of a graphite-epoxy cylinder(L/R=5, R/t=30) with a rectangular delamination of $(\mathrm{a} / \mathrm{L}=\mathbf{0 . 1 2 5}, \alpha=\pi / 4)$ and delamination thickness of a) $h_{1} / t=0.5 \quad$ b) $h_{1} / t=0.3 \quad$ c) $h_{1} / t=0.1$ 